\title{
PUPIL DILATATION IN THE PSEUDOEXFOLIATION SYNDROME
}

\author{
N. J. WATSON, S. WINDER and F. D. GREEN \\ Aberdeen
}

\section{SUMMARY}

We studied the pupil dilatation of patients with pseudoexfoliation, normals, diabetics and patients with chronic open angle glaucoma to establish whether there was a significant difference in the mydriasis achieved with cyclopentolate and phenylephrine.

Pseudoexfoliation is a difficult condition to define, the most characteristic feature being the deposition of grey-white flakes of material on the pupillary border of the iris and other anterior chamber structures. Other findings in pseudoexfoliation include pupillary ruff defects, pigment deposition on the iris surface, iris sphincter transillumination and pigment deposition in the drainage angle. ${ }^{1}$ Pseudoexfoliation has been implicated as an important risk' factor for vitreous loss during cataract surgery $^{2}$ and it has been suggested that poor dilatation is a possible cause. ${ }^{3}$

Pupil dilatation has been shown, in patients with unilateral pseudoexfoliation, to be reduced in eyes with pseudoexfoliation compared with fellow eyes. ${ }^{4}$ Anisocoria has also been found in patients with unilateral glaucoma, ${ }^{5}$ the glaucomatous pupil always being smaller than that in the normal eye. No study has specifically compared pseudoexfoliation with other causes of poor dilatation such as advanced age, diabetes, ${ }^{6}$ dark irises, ${ }^{7}$ and previous intraocular surgery. ${ }^{8}$

In order to establish whether there was a significant difference in the mydriasis achieved with a standard drop of cyclopentolate and phenylephrine, and consequently whether the surgical complications of pseudoexfoliation syndrome can be ascribed to poor pupillary dilatation, we initiated a controlled study comparing the dilatation of patients with pseudoexfoliation with that of normals, diabetics and patients suffering with chronic open angle glaucoma.

Correspondence to: N. J. Watson, Department of Ophthalmology, Aberdeen Royal Infirmary, Aberdeen AB9 2ZB, UK.

\section{MATERIALS AND METHODS}

One hundred and fifty-four patients requiring diagnostic pupillary dilatation were selected and tested in the outpatient clinics between January 1989 and October 1993. Those on any topical eye drops were excluded, as were those with obvious anterior segment pathology or a history of intraocular surgery. The patients with pseudoexfoliation therefore did not have glaucoma. These patients were matched for age with diabetic patients and patients with chronic open angle glaucoma (COAG). The patients with glaucoma were studied at their initial visit, prior to treatment.

For all patients studied, vertical pupillary diameter was measured (to the nearest $0.2 \mathrm{~mm}$ ) on a series 900 Haag-Streit slit lamp with a $1 \mathrm{~mm}$ slit width and dim illumination settings in a darkened room. One drop of cyclopentolate $1 \%$ followed 1 minute later by one drop of phenylephrine $10 \%$ was administered. The pupillary diameter was measured immediately before instillation of drops, at 5, 10, 15 and 20 minutes, and at the final dilatation achieved at 60 minutes.

\section{RESULTS}

There was no difference prior to mydriasis in the pupil size of patients with pseudoexfoliation compared with the other groups studied. After dilatation the patients with pseudoexfoliation had significantly smaller pupils than normals, diabetics or individuals with COAG. It was also noted that the pupils of patients with COAG or diabetes dilated less well than those of the control groups (Table I).

A decrease in pupil dilatation with age was noted in the normal controls but was less obvious in the other groups.

\section{DISCUSSION}

This small series shows a statistical difference in final pupillary diameter in random samples of patients 
Table I. Pupillary dilatation in patients with pseudoexfoliation syndrome, normals, diabetics and patients with chronic open angle glaucoma (COAG)

\begin{tabular}{|c|c|c|c|c|c|c|c|c|}
\hline & \multicolumn{3}{|c|}{ Comparison group } & \multicolumn{3}{|c|}{ Initial pupil size } & \multicolumn{2}{|c|}{ Final pupil size } \\
\hline & & $\begin{array}{c}\text { No. of } \\
\text { patients }\end{array}$ & $\begin{array}{c}\text { Mean age } \\
\pm \text { SD (years) }\end{array}$ & $\begin{array}{l}\text { Mean } \\
(\mathrm{mm})\end{array}$ & SD & $\begin{array}{l}\text { Mean } \\
(\mathrm{mm})\end{array}$ & SD & Significance \\
\hline \multirow[t]{2}{*}{1} & Normals & 30 & $71.4 \pm 8.7$ & 1.9 & 0.4 & 8.1 & 1.3 & \\
\hline & Pseudoexfoliative & & & 1.9 & 0.4 & 5.1 & 0.9 & $t<0.0001$ \\
\hline \multirow[t]{2}{*}{2} & Pseudoexfoliative & 18 & $73.4 \pm 7.1$ & 1.9 & 0.5 & 5.2 & 0.8 & \\
\hline & COAG & & & 2.0 & 0.7 & 6.8 & 0.9 & $t<0.0001$ \\
\hline \multirow[t]{2}{*}{3} & Pseudoexfoliative & 18 & $62.4 \pm 15.5$ & 2 & 0.4 & 5.0 & 1.0 & \\
\hline & Diabetics & & & 2 & 0.6 & 6.3 & 1.1 & $t<0.0001$ \\
\hline \multirow[t]{2}{*}{4} & Normals & 20 & $70.6 \pm 11.0$ & 1.9 & 0.5 & 7.8 & 1.3 & \\
\hline & COAG & & & 2 & 0.7 & 6.8 & 0.9 & $t<0.0001$ \\
\hline \multirow[t]{2}{*}{5} & Normals & 12 & $68.3 \pm 10.3$ & 2.1 & 0.6 & 8.2 & 1.0 & \\
\hline & Diabetics & & & 1.9 & 0.3 & 6.6 & 1.4 & $t<0.0001$ \\
\hline
\end{tabular}

with and without pseudoexfoliation when dilated with cyclopentolate and phenylephrine, and also a difference between patients with pseudoexfoliation compared with diabetics and patients with COAG.

The smaller size of pupils in patients with COAG has been previously reported. ${ }^{5}$ As pseudoexfoliation is associated with glaucoma it could be suggested that a similar mechanism causes the small pupil in patients with pseudoexfoliation or glaucoma. The pupillary dilatation problem, however, was more pronounced in the pseudoexfoliation group (none of whom had overt glaucoma).

Diabetic patients are reported to respond poorly to mydriatics, ${ }^{6}$ but we have shown that this is less pronounced than in patients with pseudoexfoliation. Increasing the pupillary dilatation, for example, from $5.5 \mathrm{~mm}$ to $7 \mathrm{~mm}$ results in an almost $60 \%$ greater pupillary area. This may be why patients with pseudoexfoliation have an increased incidence of surgical complications, as has been reported elsewhere. Other suggestions for causes of surgical difficulties in these patients include the presence of peripheral anterior synechiae, a zonular dehiscence or a thin lens capsule.

Pseudoexfoliation syndrome involves more than simple material deposition, abnormalities occurring in the lens, pupillary ruff iris and cornea. ${ }^{1}$ Even though the classic deposits are seen unilaterally the deposits may be bilateral on histological examination. ${ }^{9}$ It has been shown that pupil dilatation is poorer in eyes with obvious pseudoexfoliative

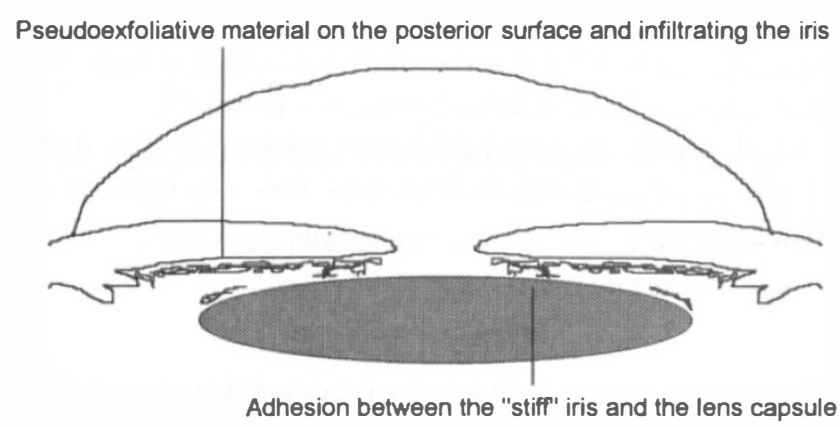

Fig. 1. The factors in the pseudoexfoliation syndrome that may cause problems in inducing mydriasis. deposits than in fellow eyes. ${ }^{4}$ This implies that it is the presence of the pseudoexfoliative material and not other aspects of the syndrome which cause the poor dilatation. The problems in inducing mydriasis may be (Fig. 1):

1. Stiffening of the iris. Pseudoexfoliative material can be demonstrated by light microscopy to be present in the anterior border layer and crypts of the iris. ${ }^{10}$ The three-dimensional honeycomb structure of pseudoexfoliative material on the iris basement membrane and bridging the iris crypts results in a rigid iris. Deeper deposition has also been reported, particularly along the blood vessels.

2. Posterior synechiae. Pseudoexfoliation fibres often effect an extensive union between the iris pigment epithelium and the pre-equatorial lens periphery. These synechiae correspond to iris transillumination defects at the sphincter. Fragments of the iris pigment layer can also be observed bound to the anterior lens capsule.

Poor pupillary dilatation is also part of the pseudoexfoliation syndrome and must be accounted for when considering risk factors for surgery in these patients.

Key words: Cyclopentolate, Mydriasis, Phenylephrine, Pseudoexfoliation syndrome.

\section{REFERENCES}

1. Prince AM, Ritch R. Clinical signs of the pseudoexfoliation syndrome. Ophthalmology 1986;93:803-7.

2. Ruprecht KW, Hoh G, Guggenmoos-Holzman T, Naumann GOH. Pseudoexfoliations-Syndrom: Klinisch-statistische Untersuchungen. Klin Monatsbl Augenheilkd 1985;187:9-13.

3. Zetterström C, Olivestedt G, Lundvall A. Exfoliation syndrome and extracapsular cataract extraction with implantation of posterior chamber lens. Acta Ophthalmol (Copenh) 1992;70:85-9.

4. Carpel EF. Pupillary dilatation in eyes with pseudoexfoliation syndrome. Am J Ophthalmol 1988;105:692-4.

5. Hahnenberger R. Anisocoria in untreated unilateral open angle glaucoma. Acta Ophthalmol (Copenh) 1984;62:135-41. 
6. Hresdarsson AB. Pupil motility in long term diabetes. Diabetologica 1979;17:145-50.

7. Levine L. Tropicamide induced mydriasis in densely pigmented eyes. Am J Optom Physiol Opt 1983;60: 673-7.

8. Gibbens M. Effects of cataract extraction on the pupil response to mydriatics. $\mathrm{Br} \mathrm{J}$ Ophthalmol 1989;73:563-5.
9. Kostas AGP, Jay JL, Marshall GE, Lee WR. Prevalence, diagnostic features, and response to trabeculectomy in exfoliation glaucoma. Ophthalmology 1993; 100:619-27.

10. Morrison JC, Green W. Light microscopy of the exfoliation syndrome. Acta Ophthalmol 1988;66 (Suppl):5-27. 